\title{
Effects of zearalenone and its metabolites on the swine epithelial intestinal cell line: IPEC 1
}

\author{
D. E. Marin, I. Taranu, G. Pistol and M. Stancu \\ National Research and Development Institute for Biology and Animal Nutrition, Balotesti, Romania
}

Zearalenone (ZEN) is a mycotoxin that can be produced by several Fusarium fungi ${ }^{(1,2)}$ and it exists widely in maize, barley, wheat, oats, sorghum and sesame seeds, as well as in hay and corn silage, which are ingredients in many food products for humans or animals ${ }^{(3)}$. ZEN can be bound to the estrogen receptors ${ }^{(4,5)}$ resulting in a hyperestrogenicity syndrome in several animal species, especially pigs ${ }^{(6)}$. In addition, ZEN has been shown to be immunotoxic ${ }^{(7)}$, hepatonephrotoxic ${ }^{(8)}$ and enhancer of lipid peroxidation ${ }^{(9)}$.

Using in vitro approaches, we have investigated the effect of ZEN and its metabolites: alpha zearalenol (a-ZOL) and beta zearalenol (b-ZOL) on a pig epithelial cell line: IPEC-1, in term of cell viability, trans-epithelial electric resistance (TER) and synthesis of some inflammatory cytokines: IL-1 beta; TNF alpha and IL-8. For the viability assays, IPEC-1 cells were cultivated in 96 wells plates and treated or not with 0.1-100 M ZEN and metabolites. The TER and cytokine synthesis assays were performed using cells cultivated in transwell inserts and treated for 9 days with ZEN and metabolites (25 and $50 \mathrm{M})$. Using an XTT and a neutral red assay we have shown that both ZEN and ZEN metabolites induced a dose dependent decrease of cell viability, with beta-ZOL being the most toxic.

The trans-epithelial electric resistance measurement, showed that $25 \mathrm{M}$ of beta ZOL induced a light increase of TER values but no effect was observed for ZEN or alpha ZOL. At $50 \mathrm{M}$, alpha and beta ZOL induced a time decrease of TER values, all along the experiment; thus at day 9, the TER value in the treated inserts were $17.8 \%$ for alpha ZOL and $21.6 \%$ for beta ZOL from the unintoxicated control. By contrast, ZEN induced only a slight decrease of the TER values, that was retrieved at day 9 (95.6\% in ZEN treated insert compared with $100 \%$ in the control).

The analyse of the cytokine concentration in the supernatant from the apical (AC) and baso-lateral (BC) compartments of the inserts showed that the IPEC-1 cells were not able to synthesize IL-1 beta or TNF alpha. By contrast, IPEC-1 cells were able to synthesize IL-8; the synthesis was similar among the treatments in the BC, but an induction of the IL-8 synthesis by the toxins was observed in the AC. Taken together, our results showed that ZEN and its metabolites could interfere with the barrier function of the intestine and with the capacity of the intestinal cells to realise an inflammatory response.

1. Richard JL (2007) Int. J. Food Microbiol 119, 3-10.

2. Bennett JW \& Klich M (2003) Clin Microbiol Rev 16, 497-516

3. Tabuc C, Marin D, Guerre P, Sesan T, Bailly JD (2009) J Food Prot 72, 662-665.

4. Boyd PA \& Wittliff JL (1978) J Toxicol Environ Health 4, 1-8.

5. Takemura H, Shim JY, Sayama K et al. (2007) J Steroid Biochem Mol Biol 103, 170-177.

6. Minervini F \& Dell'aquila ME (2008) Int J Mol Sci 9, 2570-2584.

7. Luongo D, De Luna R, Russo R \& Severino L (2008) Toxicon 52, 156-162.

8. Bouaziz C, Sharaf El Dein O, El Golli E et al. (2008) Toxicology 254, 19-28.

9. Zourgui L, Golli EE, Bouaziz C, Bacha H, Hassen W (2008) Food Chem Toxicol 46, 1817-1824. 